\title{
Creating a New Ethical Climate for Drug Research in Children and Pregnant Women
}

\author{
Doreen Matsui • Gideon Koren
}

(C) Springer International Publishing Switzerland 2015

Most medications given to infants, children, and pregnant women have not been labeled by regulatory agencies for use in these vulnerable groups. This often means that appropriate studies examining efficacy and safety, at the level demanded by the regulators, have not been conducted. Yet, it is important to acknowledge that many such studies have been and are being performed even without industry's interest, by academics in numerous pediatric departments. We applaud these individuals, as they have not just accepted the reality that children and pregnant women are orphaned from the benefits of new and existing therapies. We also applaud the American government for leading the world in demanding and enforcing the pharmaceutical industry to conduct such studies by extending patent protection, as well as initiating large-scale studies on older, 'off patent' drugs. Europe has followed the American leadership, and it is hoped that other jurisdictions will also find ways to value the child, before and after birth, as worthy of benefiting from appropriately investigated therapy.

This article is part of the topical collection on Ethics of Pediatric Drug Research.

D. Matsui $(\bowtie)$

Departments of Paediatrics and Medicine, Children's Hospital, London Health Sciences Centre, Child Health Research Institute, University of Western Ontario, 800 Commissioners Road East, London, ON N6A 5W9, Canada

e-mail: dmatsui@uwo.ca

\section{G. Koren}

Division of Clinical Pharmacology and Toxicology at the Hospital for Sick Children, University of Toronto, 555 University Ave, Toronto, ON M5G 1X8, Canada e-mail: gkoren@sickkids.ca
The challenges of conducting ethically sound research in children are numerous. Many of the issues arise from the fact that the research subject cannot decide for himself/ herself, and informed decisions need to be made by parents or other guardians. Challenges also stem from the differences in drug handling in young infants due to organ immaturity, the potential increased risk of toxicity in ill children and the possibility of long-term developmental effects that may not be detected until years later.

This theme issue of Pediatric Drugs is dedicated to discussing ethical challenges encountered in conducting drug research in infants, children, and pregnant women, and to identifying solutions that may enable clinician scientists and other pediatric researchers to conduct such studies.

Topics covered herein include defining and measuring risks and benefits inherent in pediatric clinical research [1], consent and assent [2], and equipoise [3]. The theme issue also addresses the specific ethical considerations encountered when conducting research in different pediatric subpopulations, from the fetus [4] and newborns [5] to the adolescent [6], the developmentally challenged child [7], and the child with cancer [8]. Certain clinical situations are particularly challenging from a research ethics perspective and are covered in detail in this issue, including intensive care [9], the emergency department [10], and low-income countries [11]. Moreover, although a common set of regulations seem to operate around the world, they have not been interpreted uniformly by different jurisdictions and, therefore, in an attempt to be generalizable, we have tried to address these sources of variability, when appropriate.

The Research Ethics Committee plays a pivotal role. Countries who are members of the World Medical Association are in agreement that the conduct of ethical research should reside in the hands of committees, referred to in 
different regions as Research Ethics Boards (REBs), Research Ethics Committees, Institutional Review Boards, or the Helsinki Committee, to commemorate the original Helsinki accord on ethics.

Guidance documents that provide an ethical framework for pediatric research vary depending on location. In Canada, the Tri-Council Policy Statement (TCPS2) has been adopted as a benchmark for the ethical conduct of research involving humans. According to this document, each institution is accountable for the research carried out in its jurisdiction and responsible for ensuring REB review of the ethical acceptability of that research [12]. REBs and investigators should work in conjunction to ensure the protection of participants in research studies [13]. The basic ethical principles of respect for persons (autonomy), beneficence, and justice, as outlined in the Belmont Report [14] should be considered. There should be members of the REB who have relevant knowledge and expertise to understand the content area and methodology of the proposed study and to assess the associated risks and benefits [12]. Individuals with a background in law and ethics as well as community representatives to provide a lay perspective should also be invited to participate. The membership of REBs that review studies involving children should also include someone with experience in research in this age group. The saying "children are not just small adults" certainly does apply to the ethics review process.

There are generally two levels of research ethics review, consisting of full board review and delegated review of minimal risk research [12]. As children are considered to be a vulnerable group in need of special protection, the cautious approach tends to be to review protocols at the full board level if there is any doubt. What constitutes minimal risk in children is not clear cut and often debated [15]. A telephone survey study [16] found substantial variability in Institutional Review Board chairpersons' assessments of the level of risk associated with various research procedures in children. In reviewing pediatric studies, special attention is generally paid to determining the risk-benefit balance. Other controversial issues in children that may require REB deliberation are the use of placebo controls, the recruitment of healthy volunteers, the appropriateness of assent, and the inclusion of financial or other incentives. Variability in REB decisions among centers may be seen, and differing interpretations resulting from somewhat unclear guidelines specific to children may be a contributing factor, as eloquently described in this issue by Needham et al. [17]. Another growing area of research covered here is that of pharmacogenetics, which has led to REBs (and researchers) encountering additional ethical dilemmas such as the collection of biological specimens for banking, and dealing with the future implications of results found in a child who did not initially consent to be studied [18].
In an Australian study, 34 research ethics committee members and 54 health researchers were interviewed as to their perception of the role of human research ethics committees [19]. Both groups agreed that the primary role is the protection of research participants, with ethics committee members also thinking that they were responsible for ensuring that research is beneficial. Interestingly, some researchers commented that ethics committees were sometimes overprotective and paternalistic toward research participants. A 'gatekeeper' or 'filtering' role, assisting researchers to ensure their research was ethically rigorous, was described, although some researchers believed that ethics committees have the capacity to prevent research from being conducted, which they believed was inappropriate. The role of ethics committees to comment on methodology was particularly contentious, as some researchers considered ethics committees to be overly prescriptive. Conflicting understandings about the role of ethics committees may culminate in an adversarial relationship, with the ethics review process viewed as a hurdle to overcome [19].

As noted above, whether it is the role of the REB to evaluate the appropriateness of the proposed research methodology and to judge the scientific merit of a study is a matter of debate. However, it has been stated that "poor science has ethical consequences" [20, 21]. A study that is not of sound design will subject participants to inconvenience and potential harm without the prospect of generating useful results. Precious resources and time will be wasted. Allowing a flawed study to proceed is thus unethical, and assessment of a study's science and feasibility should be part of its ethical review [21].

Consideration of the ethics of a research study, whether in the initial approval of a study or as the study is being conducted, should be viewed as an ongoing and necessary process. REB members and researchers must work collaboratively to ensure the common goal of protection of pediatric research participants. The REB should not be seen as obstructive and authoritative. Communication between both parties brings about resolution of most issues. The REB also has a role to play in educating researchers regarding the application of the basic ethics principles and the ethical challenges of conducting research studies in children and should be available to researchers to guide them through the process of ethics review.

We hope that this theme issue of Pediatric Drugs will help pediatric researchers, regulators, students, parents, and other members of the public at large in the conduct of drug studies in children and pregnant women. Being paralyzed by fears of involving children and pregnant women in clinical drug trials means that we will continue to give them untested or sub-optimally studied medications, hence endangering their lives and well-being. This situation is 
unacceptable and must be replaced by well informed and carefully executed courage. We hope that the present theme issue can serve as a road map for such transformation.

Acknowledgments No sources of funding were used to assist in the preparation of this article. D. Matsui and G. Koren have no conflicts of interest related to the content of this article.

\section{References}

1. Koren G. A practical approach to risk-benefit estimation in pediatric drug research. Pediatr Drugs. 2015;17(1):13-6.

2. Leibson $\mathrm{T}$, Koren G. Informed consent in pediatric research. Pediatr Drugs. 2015;17(1):5-11.

3. Chau K, Koren G. The principle of equipoise in pediatric drug trials. Pediatr Drugs. 2015;17(1):17-21.

4. Matsui D. Ethics of studies of drugs in pregnancy. Pediatr Drugs. 2015;17(1)31-5.

5. Ward RM, Sherwin CMT. Ethics of drug studies in the newborn. Pediatr Drugs. 2015;17(1):37-42.

6. Welisch E, Altamirano-Diaz LA. Ethics of pharmacological research involving adolescents. Pediatr Drugs. 2015;17(1)55-9.

7. Rumney P, Anderson JA, Ryan SE. Ethics in pharmacologic research in the child with a disability. Pediatr Drugs. 2015;17(1):61-8.

8. Schechter T, Grant R. The complexity of consenting to clinical research in phase I pediatric cancer studies. Pediatr Drugs. 2015;17(1):77-81.

9. Kleiber N, Tromp K, Mooij MG, van de Vathorst S, Tibboel D, de Wildt SN. Ethics of drug research in the pediatric intensive care unit. Pediatr Drugs. 2015;17(1):43-53.
10. Neuman G, Shavit I, Matsui D, Koren G. Ethics of research in pediatric emergency medicine. Pediatr Drugs. 2015;17(1):69-76.

11. Macleod S, Knoppert DC, Stanton-Jean M, Avard D. Pediatric clinical drug trials in low-income countries: key ethical issues. Pediatr Drugs. 2015;17(1):83-90.

12. Canadian Institutes of Health Research, Natural Sciences and Engineering Research Council of Canada, and Social Sciences and Humanities Research Council of Canada. Tri-council policy statement: ethical conduct for research involving humans. 2010.

13. Cummings L. Get on board with the research ethics review process. Can Nurse. 2012;108:28-33.

14. The National Commission for the Protection of Human Subjects of Biomedical and Behavioral Research. The Belmont ReportEthical Principles and Guidelines for the Protection of Human Subjects of Research. 1979. http://www.hhs.gov/ohrp/human subjects/guidance/belmont.html. Accessed 31 July 2014.

15. Westra AE, Wit JM, Sukhai RN, de Beaufort ID. How best to define the concept of minimal risk. J Pediatr. 2011;159:496-500.

16. Shah S, Whittle A, Wilfond B, Gensler G, Wendler D. How do institutional review boards apply the federal risk and benefit standards for pediatric research? JAMA. 2004;291:476-82.

17. Needham AC, Kapadia MZ, Offringa M. Ethics review of pediatric multi-center drug trials. Pediatr Drugs. 2015;17(1):23-30.

18. Madadi P. Ethical perspectives on translational pharmacogenetic research involving children and pregnant women. Pediatr Drugs. 2015;17(1):91-5.

19. Guillemin M, Gillam L, Rosenthal D, Bolitho A. Human research ethics committees: examining their roles and practices. J Empir Res Hum Res Ethics. 2012;7:38-49.

20. Greaney AM, Sheehy A, Heffernan C, Murphy J, Mhaolrúnaigh SN, Heffernan E, Brown G. Research ethics application: a guide for the novice researcher. Br J Nurs. 2012;21(1):38-43.

21. Dawson AJ, Yentis SM. Contesting the science/ethics distinction in the review of clinical research. J Med Ethics. 2007;33:165-7. 